\title{
Gd-Sm (Gadolinium-Samarium)
}

\section{H. Okamoto}

The Gd-Sm phase diagram in [Massalski2] was redrawn from [1983Gsc]. The two two-phase fields, $\mathrm{L}+(\beta \mathrm{Gd}, \gamma \mathrm{Sm})$ and $(\beta \mathrm{Gd}, \gamma \mathrm{Sm})+(\alpha \mathrm{Gd}, \beta \mathrm{Sm})$, are so narrow that they were shown with straight lines. The $(\alpha \mathrm{Sm})$ phase field was drawn vertically at $\left(0{ }^{\circ} \mathrm{C}, 60\right.$ at. $\%$ Sm $)$ and smoothly connected to the $\beta \mathrm{Sm} / \alpha \mathrm{Sm}$ transition temperature $\left(734{ }^{\circ} \mathrm{C}\right)$ at 100 at. $\% \mathrm{Sm}$. This is based on the literature data that the maximum solubility of $\mathrm{Gd}$ in $(\alpha \mathrm{Sm})$ is 40 at. $\%$.

Figure 1 shows the Gd-Sm phase diagram calculated by [2010Guo]. The narrow two-phase fields shown by [1983Gsc] could be reproduced, but the shape of the $(\alpha \mathrm{Sm})$ phase field appeared differently. The shape shown in
Fig. 1 is preferred because it is based on thermodynamics. Because there are no reliable experimental data, the trend of the $(\alpha \mathrm{Sm})$ phase boundary is still tentative.

\section{References}

1983Gsc: K.A. Gschneidner, Jr. and F.W. Calderwood, The Gd-Sm (Gadolinium-Samarium) System, Bull. Alloy Phase Diagr., 1983, 4(2), p 164-167

2010Guo: C. Guo, Z. Du, and C. Li, A Thermodynamic Description of the Gd-Mg-Sm System, Calphad, 2010, 34, p 90-97

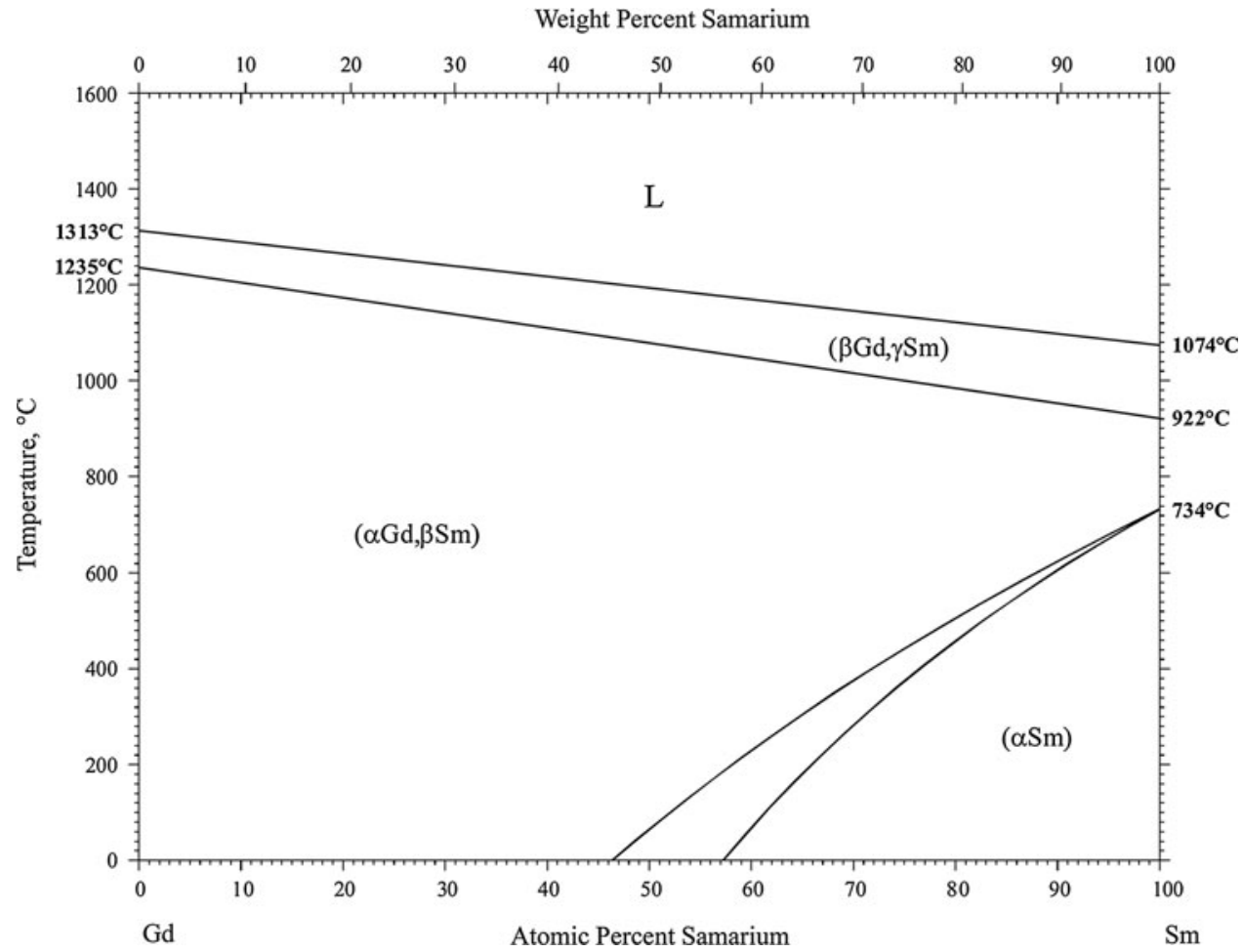

Fig. 1 Gd-Sm phase diagram 